\title{
Computing, Design, Art: Reflections on an Innovative Moment in History
}

Stephan Boyd Davis, Simone Gristwood ${ }^{* *}$

${ }^{*}$ Royal College of Arts, UK

${ }^{* *}$ Middlesex University, UK

Our paper is concerned with the role of art and design in the history and philosophy of computing. We offer insights arising from our research into a period in the 1960 s and 70 s, particularly in the UK, when computing became more available to artists and designers, focusing on John Lansdown (1929-1999) and Bruce Archer (1922-2005) in London. ${ }^{1}$ We suggest that models of computing interacted with conceptualisations of art, design and related creative activities in important ways.

The kinds of approaches Archer and Lansdown were advocating could be seen to have roots much further back in the history of computing. Babbage identified two qualitatively different applications of complex machinery. His designs for the Difference and Analytical Engines were for machines primarily tasked to do useful work, but Babbage's prized possessions included an automaton dancer and a portrait of Joseph Marie Jacquard woven on a Jacquard loom. For Babbage, the latter represented the idea that apparently humanistic, artistic creations could be arrived at by mechanical means [10, pp. 107-8]. Much

One of the present authors, Stephen Boyd Davis was a colleague of Lansdown 1988-1999 and interviewed him in 1988 when he joined Middlesex University, the other, Simone Gristwood, is working on the archives of Lansdown and of Archer and the Department of Design Research at the RCA and V\&A. has since been written on Babbage and Lovelace's speculations on the relation of computational machines to creativity. A century later, these questions were addressed afresh by Lansdown, Archer and others through the lens of the arts and design. However, in subsequent years, much art and design thinking has been dominated by the notion of the computer as merely a tool, no more important intellectually than a trowel, an airbrush or a scalpel: our aim is to help recover some of that lost intellectual engagement of art and design with the special qualities of computing.

Lansdown and Archer were working at a time when there was great optimism in the use of computers across the UK, Europe, and indeed, the world. This was demonstrated not least by important exhibitions such as Cybernetic Serendipity (1968) at the ICA and Event I (1969) at the Royal College of Art in London, and New Tendencies from 1968 in Croatia as well as the Venice Biennale computer arts exhibitions to name a few. There were also connections between the arts, design and computing through figures such as German philosopher Max Bense, who was not only involved in one of the first computer arts exhibitions in Stuttgart in 1965 , but also taught at the influential UIm School of Design in the 1950s, where Archer was a visiting scholar from $1960-62$.

Important influences on Lansdown and 
Archer were mid-century ideas on information theory, systems theory, operational research (OR) and cybernetics. Lansdown was a partner in a large architectural firm, investigating the application of OR and uses of mathematics that required computing [4]. OR offered systematic decision-making using mathematical and statistical approaches. Applied to design, it emphasized sequential processes such as gathering data and requirements, weighting these before proceeding to designing. A similar interest led Archer to computing, as he saw its logic as a way of generating 'effective systematic methods for solving design problems' [ 1, p. I]. Archer's early influential publications, Systematic Methods for Designers [2] and The Structure of Design Processes [3], show a strong influence of algorithmic thinking.

Things became interesting when Lansdown and Archer each considered linear algorithmic models of designing in the light of actual practice in design and the arts. A crucial realisation was that effective designing cannot occur where the requirements-gathering process is effectively closed before designing begins. Lansdown suggested that 'design is not an algorithmic process in which the designed conclusions can be reached by the operation of step-by-step procedures - first finalising this aspect, then that. It is a fluid, holistic process wherein at any stage all the major parts have to be manipulated at once' [8, p. 3]. Cybernetics, with its emphasis on feedback and auto-reconfiguring - supporting a model where design does not follow research, but interacts with it - is clearly important here; Archer cited Beer, Pask and Ashby in his thesis [3] where he argued that designing always tends to raise new questions and new information needs that could not have been foreseen at the beginning.

While Archer's preoccupation was primarily with design, Lansdown's interest ran- ged wider, with work spanning architecture, computer graphics, choreography, design education and artificial intelligence. A founder member of the Computer Arts Society, he edited their newsletter, PACE, which engaged internationally with discussions about computers in the arts in the broadest sense. He also wrote a regular column from 1974 to 1992 for the Computer Bulletin that provides a unique insight into his thinking and that of his contemporaries. For him, computing could be a simulator, creative interlocutor, expert system, or information environment - among other roles. In 1970 he discussed computer-based vocabularies that would enable the programmer to 'simulate creativity in widely differing areas' [9, p. 9]. An important landmark was his work on computer-generated choreography [5]. Lansdown said that from c1962 onwards, 'familiar with some of the attempts to utilize the computer to compose poetry or prose, to produce kinetic sculpture, or to create music, I tried to draw common principles from these efforts to apply to ballet' [6, p. 19]. Practical work began in 1969. Perhaps most significantly he claimed that, 'The appeal of computer art lies in the procedures used to produce it - the computer methods used are as interesting to the artist as the final outcome' [6, p. 21] - a far cry from the more or less invisible computing that now supports many aspects of the creative arts and industries. A few years later, he remarked on 'the really difficult problems [...] that confront anyone working in this field' [7, p. 17] - important feedback from the realities of embodied performance.

Lansdown and Archer had influential roles, each leading a pioneering research centre in his respective university, and affecting, through publication and senior advisory roles on the Science Research Council and Design Council, policy on computing, design, design management, the arts and other fields. Archer 
retired from the RCA in 1988. Lansdown continued, until his death a decade later, to champion the idea that computing was not just a medium or tool, but an intellectual challenge whose possibilities deserve active, ostensive investigation. Recently, such approaches to computing among artists and designers are

\section{References}

[1] L.B. Archer, "Lecture to Architectural Association School of Architecture [...]", Bruce Archer Archive, Royal College of Art, 1963.

[2] L.B. Archer, Systematic Method for Designers. London: The Design Council, 1965.

[3] L.B. Archer, The Structure of Design Processes. Springfield, VA: U.S. Department of Commerce, 1968.

[4] S. Boyd Davis, Interview with John Lansdown, London, 21 July 1988.

[5] J. Lansdown, "Computing and the Design Function of the Architect", in Proceedings International Conference on Computers in Architecture, 1972. once again finding adherents, whether in livecoding by musicians and sound artists, 'maker faires', or in increased interest in overtly algorithmic art. These developments and their antecedents are important components in the history and philosophy of computing.

[6] J. Lansdown, "The Computer in Choreography". Computer 11(8). 19-30, 1978.

[7] J. Lansdown, "Not Only Computing - Also Art". Computer Bulletin 17. 17, 1980.

[8] J. Lansdown, "The Impact of SERC funding on CAAD and Design Methods [...]". John Lansdown Archive, Middlesex University, JLA/1/2/1 Box 3, 1983.

[9] J. Lansdown, "Computing in the Creative Professions". John Lansdown Archive, Middlesex University, JLA/1/1/177 Box 1, 1985.

[10] D. Swade, The Cogwheel Brain. Charles Babbage and the Quest to Build the First Computer, London: Little, Brown, 2000. 